\title{
Assessment of nanobag as a new safety system in the frontal sled test
}

\author{
Jan Špička ${ }^{a^{*}}$, Tomasz Bońkowski ${ }^{\mathrm{a}}$, Luděk Hynčík ${ }^{\mathrm{a}}$, and Alojz Hanuliak ${ }^{\mathrm{b}}$ \\ ${ }^{a}$ Department of Biomechanical human body models, New Technologies - Research \\ Centre, University of West Bohemia, Plzeň, Czech Republic;
}

${ }^{b}$ EB safety systems, Brno, Czech Republic

*Corresponding author: spicka@ntc.zcu.cz

\begin{abstract}
Objective: The future mobility challenges leads to considering new safety systems to protect vehicle passengers in non-standard and complex seating configurations. The objective of this study is to assess the performance of a brand new safety system called nanobag and to compare it to the traditional airbag performance in the frontal sled test scenario.
\end{abstract}

Methods: The nanobag technology is assessed in the frontal crash test scenario and compared with the standard airbag by numerical simulation. The previously identified material model is used to assemble the nanobag numerical model. The paper exploits an existing validated human body model to assess the performance of the nanobag safety system. Using both the new nanobag and the standard airbag, the sled test numerical simulations with the variation of human bodies are performed in $30 \mathrm{~km} / \mathrm{h}$ and $50 \mathrm{~km} / \mathrm{h}$ frontal impacts.

Results: The sled test results for both the nanobag and the standard airbag based on injury criteria shows a good and acceptable performance of the nanobag safety system compared to the traditional airbag.

Conclusion: The results show that the nanobag system has its performance compared to the standard airbag, which means that thanks to the design, the nanobag safety system has a high potential and extended application for multidirectional protection against impact.

Keywords: advanced vehicle safety; standard airbag; nanobag; frontal sled test 


\section{Introduction}

The vehicle safety is as old as mobility started. The improvement of vehicle occupant's safety was approached in different ways, where all of them led to enforcing the vehicle manufacturers by embedding safety standards into legislation and policies. Whilst the history of safety belts dates back to the early $20^{\text {th }}$ century, the airbag has come more than 50 years later (Schmitt et al., 2013). Although the active systems strongly support the present vehicle safety, the passive systems still play a main role. Nowadays, the airbag is an inherent safety system in almost all road vehicles protecting passengers not only in frontal and side impacts but special airbag systems mitigate the injury of other parts of the human body (knee, chest etc.).

Current trends in the automotive industry bring new challenges for active and passive safety technology. Non-traditional seating configurations in autonomous vehicles and complex crash scenarios including multi-directional impacts are to be considered (Jorlöv et al., 2017) in the future vehicles. The expected future scenarios will cover complex and highly unpredictable loading from various directions. This study is testing a new restrain system, that can find its benefit in these non-standard seating configurations, where standard airbag can lose its performance. However, the nanobag technology need to be tested and certified firstly in the standard seating position. Moreover, the main aim here is to assess the performance of the nanobag compare to standard airbag, and it is certified for standard seating configuration only. Thus, only the standard seating configuration and frontal impact are considered in this study.

The aim of this study is to assess a brand new concept of the interior safety system for front and back seats made of elastic ultralight materials (Hanuliak et al., 2018). The assessment concerns a virtual numerical simulation using validated models of both the occupant and the restrain system. The new supplemental restraint system called nanobag 
concerns a foil folded in front of the passenger to serve as an airbag. The system is built in the way that it can be easily adapted for side impact. The main advantages of this new technology are in the minimizing the volume of the folded airbag, decreasing the car weight, simplicity of the technology production and maintenance, low cost of materials, including the assembly and possible applicability to the multidirectional accident scenarios with non-standard seating configurations, which is going to be a critical issue within new technologies of future mobility ecosystem.

For assessing the safety of future mobility, the traditional anthropometric testing devices (dummies) are not suitable due to its unidirectional bio-fidelity, which cannot address the non-traditional seating. The new state-of-the art ATD's (THOR) are still in the process of exploration for the automated vehicles crash scenarios application (Wang et. Al, 2019) Therefore, the paper utilised an existing validated human body model (Vychytil et al., 2014).

\section{Methods}

The study adopts the new safety system documentation for the nanobag (Hanuliak et al., 2018) and the hybrid numerical virtual human body model Virthuman (Vychytil et al., 2014) in the standard frontal sled test scenario within the defined acceleration pulse simulating $30 \mathrm{~km} / \mathrm{h}$ and $50 \mathrm{~km} / \mathrm{h}$ collisions (Vezin et al., 2002). The computational approach using validated numerical human model is used for assessing the performance of the new vehicle safety system in the frontal sled test with the identified material of the nanofoil. The nanobag concerns a thin foil (nanofoil) unrolled between side supports. The nanofoil is based on a linear low-density polyethylene (LLDPE), where the material properties were previously identified in both static and dynamic loading conditions (Hynčík et al., 2021). The frontal scenario was chosen as the first step for assessing the performance of the nanobag system due to the easiness of comparison to the standard 
airbag performance. The entire numerical tests were performed under the ESI Virtual Performance Solution (VPS) package (ESI Group). The injury risk of the most threatened body parts was monitored by the selected injury criteria (Schmitt et al., 2013).

\section{Occupant selection}

The aim of the study was to compare the performance of both safety systems (the traditional airbag and the new nanobag) for a spectrum of population by selecting the specific occupant anthropometry to be tested in the frontal sled test with the particular safety features. Authors chose the specific subjects based on the anthropometry of Czech Republic population representing the average European population and selected the "local peaks" of the population only, see Figure 1.

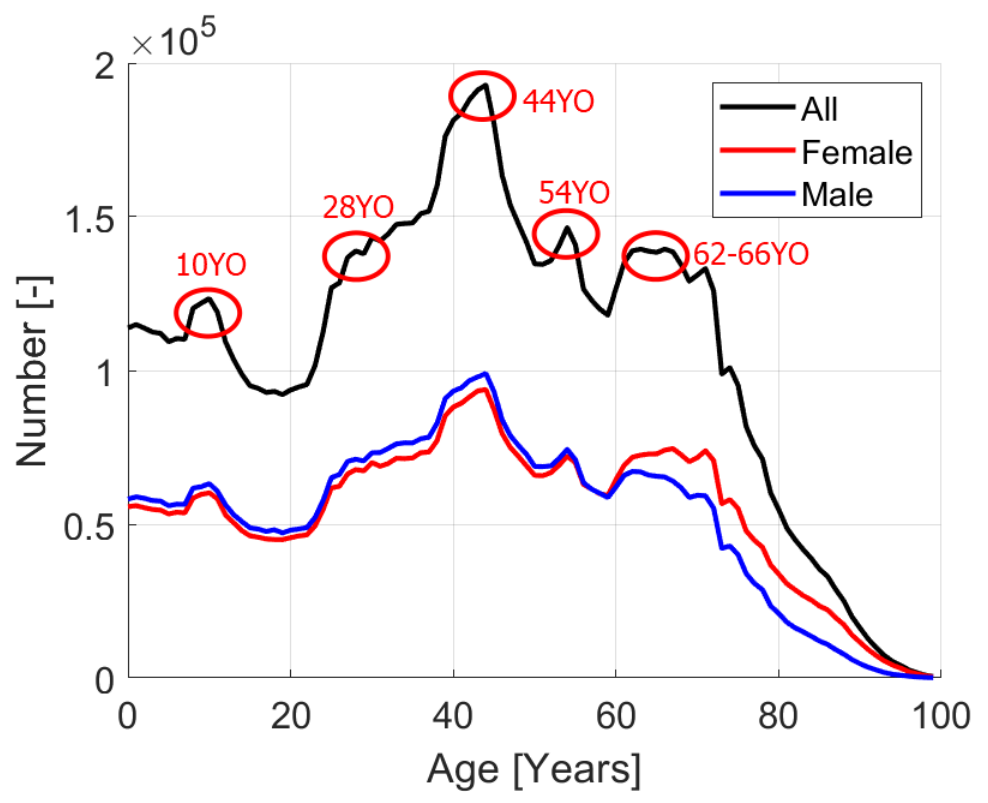

Figure 1: Population of the Czech Republic in 2019 (source: Czech Statistical Office)

Figure 1 shows the representation of the age groups in the Czech population. The peaks show the highest representation for 10, 28, 44, 54 and $62-66$ years old (further referred as $\mathrm{YO}$ ) for both males $(\mathrm{M})$ and females $(\mathrm{F})$. As the comparison concerns frontal seat impact, the youngest group was selected to be in-line with the Czech Republic regulation 
for the front seat height limit, which is a passenger higher than $150 \mathrm{~cm}$. Thus, the youngest age group was chosen in order to have the female higher than $150 \mathrm{~cm}$ (here $14-15 \mathrm{YO}$ ). Additionally, percentiles P50 and P95 for the male and P5 of the female from each age interval (in correspondence with the dummy size) were implemented. The particular intervals are defined from the Virthuman model and its internal scaling algorithm, where the age is defined in the intervals (not a single value) (Hynčík et al., 2013). Thus, the specified age groups are selected based on Figure 1, but defined with respect to the Virthuman model scaling, where the age are define by the intervals. The list of the selected occupants are as follows:

Table 1: Selected occupant anthropometries of Virthuman model

\begin{tabular}{|c|c|c|c|c|}
\hline Age & Gender & $\mathbf{P}$ & $\mathbf{h}[\mathbf{c m}]$ & $\mathbf{m}[\mathbf{k g}]$ \\
\hline \multirow{3}{*}{$14-15$} & $\mathrm{M}$ & 50 & 170 & 57 \\
\cline { 2 - 5 } & $\mathrm{M}$ & 95 & 180 & 70 \\
\cline { 2 - 5 } & $\mathrm{F}$ & 5 & 152.6 & 41.4 \\
\hline $25-30$ & $\mathrm{M}$ & 50 & 178 & 76 \\
\cline { 2 - 5 } & $\mathrm{M}$ & 95 & 187 & 94 \\
\cline { 2 - 5 } & $\mathrm{F}$ & 5 & 158 & 52.5 \\
\hline $35-45$ & $\mathrm{M}$ & 50 & 174 & 79 \\
\cline { 2 - 5 } & $\mathrm{M}$ & 95 & 185.5 & 96.3 \\
\cline { 2 - 5 } & $\mathrm{F}$ & 5 & 154.3 & 52.5 \\
\hline $45-55$ & $\mathrm{M}$ & 50 & 172.3 & 78.5 \\
\cline { 2 - 5 } & $\mathrm{M}$ & 95 & 184.4 & 96 \\
\cline { 2 - 5 } & $\mathrm{F}$ & 5 & 154.2 & 55 \\
\hline $55-65$ & $\mathrm{M}$ & 50 & 171.9 & 83 \\
\cline { 2 - 5 } & $\mathrm{M}$ & 95 & 180.2 & 95 \\
\cline { 2 - 5 } & $\mathrm{F}$ & 5 & 153.5 & 60 \\
\hline
\end{tabular}

\section{Human body model}

The study implements Virthuman as a hybrid model combining the advantages of the deformable elements based on finite element methods (FEM) coupled to the multibody structure (MBS) (Vychytil et al., 2014). The deformable elements, representing the external shape of the human body, are connected via non-linear springs and dampers to 
the rigid segments. Such segments form an open tree structure based on the multibody principle. The particular rigid segments are connected via kinematic joints representing the real human joints (shoulder, elbow, knee, etc.) or breakable joints for description of the bone fracture.

The Virthuman model is a fully scalable human body model taking into account gender, age, height (h) and weight (m) of the particular subject (Hynčík et al., 2013), where the wide set of a human anthropometric database (Bláha, 1987) is the basement of the automatic scaling algorithm implemented in the model.

The Virthuman model was validated against a large set of validation tests. The full-body tests for various traffic scenarios (Bońkowski et al., 2019, Lindstedt et al., 2016, Lv et al., 2019) and body sizes (Hynčík et al., 2014, Hynčík et al., 2015) as well as detailed tests for the particular human body segments (Vychytil et al., 2014) were performed to ensure the biofidelity of the Virthuman model. This model is MBS based using the deformable elements (virtual springs, dampers and kinematic joints with internal stiffness or breakable joints) to consider the deformability of the human body. It does not include internal structures and internal organs. However, the deformability and injury risk could be assessed are taking into account through injury criteria coupled with the injury risk curves. The criteria are calculated based on the mechanical quantities, such as accelerations, velocities, forces, torques etc.

\section{Safety system}

This paper implemented two supplemental restraint system (SRS) into the frontal sled test scenario - namely the standard airbag and new system called nanobag, together with the standard three points seat belt. 


\section{Airbag}

The previously utilized model of the standard airbag (referred as AB in figures and tables) was used for the simulations (Vychytil et al., 2014). The undeployed airbag model is fixed to the steering wheel and the deploying process runs within the simulation. The airbag is activated at the begging of the simulation, for both simulations. The airbag starts the deploying process within the simulation, defined via the characteristics of the airbag in the VPS software. The airbag is modelled as a single chamber, with all its features, such as inflating or leakage.

\section{Nanobag system}

Nanobag (later referred as NB in figures and tables) system consists of two thin layer curtain folded in front of the occupant. Such technology consists of elastic wall, brackets, gas generator and controlling system, see Figure 2. They are arranged under the roof and deployed under sensor activation (similarly to the standard airbag). The simplified geometry of the nanobag system was built based on the documentation provided by Hanuliak et al. (2018). The study implements the previously identified linear low density polyethylene LLDPE nanofoil material (Hynčík et al., 2021). Hynčík et al., 2021 performed the numerical optimization of material parameters to fit the performed experimental tests. Static and dynamical analysis were considered to model and validate the material behaviour for such loading. The nanobag is considered as a several layers of such LLDPE foil. The number of layers is one of the main parameter of the safety assessment of this technology and it is to be tested. 

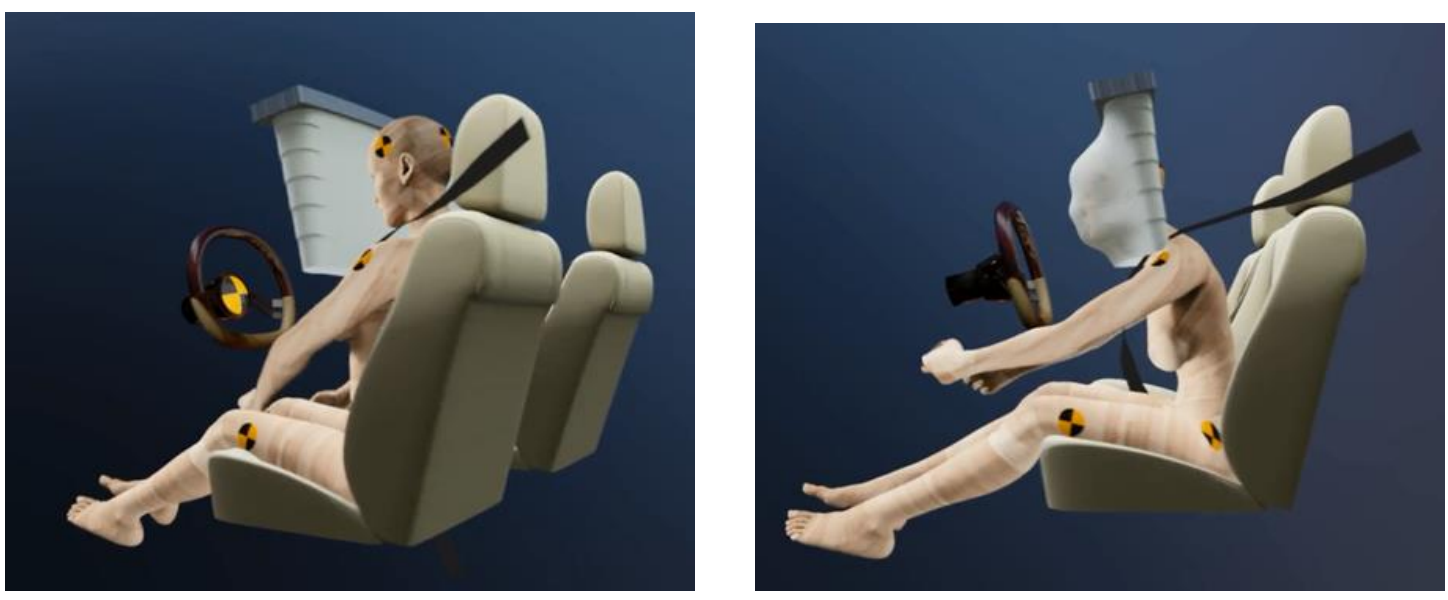

Figure 2: Nanobag system

For the assessment of the safety performance, the nanobag support frame is considered as a rigid body and the nanobag is considered to be deployed at the beginning of the simulation. The process of the deployment (unfolding) of the nanobag was not considered in this study. The inclination of the nanobag support to the cushion seat is $25^{\circ}$ for the inner layer and $30^{\circ}$ for the outer layer. The position of the seat and the nanobag was equal for all the configurations. In order to respect adjusting of the seat and to model the experimental test correctly, the footrest was adjusted closely to the feet (the feet are in the close contact with the footrest), see Figure 3. The nanobag rigid frame is considered to be fixed to the car roof (into the reinforcement). However, since this system is still under development and not has been tested and certified, the particular design and method of fixing to the frame is not considered in this study.

\section{Seat belts}

The model is seated as a driver and fastened with the seatbelt using the semi-automatic tool build implemented in the VPS software, with the default material properties of the seat belt. For the simplicity, the seat is considered as a rigid. In order to represent a more realistic case, the hands were considered for the contact with the steering wheel (Happee et al., 2008). The seat belt consists of the membrane elements (in the part of contact with 
the body) and bar elements (in the connection to a retractor, slipring and buckle respectively). The material characteristics of these structures are defined (and previously validated in VPS software).

\section{Sled test scenario}

The standard frontal sled test scenario was used here (Vezin et al., 2002). The configuration based on the previous tests (Vychytil et al., 2014) consists of the seat fixed to the rigid frame, 3-point seat belt system and the particular elements of the passive safety (airbag or nanobag). The steering wheel was also included (to fix the airbag) and it is being modelled as a rigid. The motion of the sled device was defined by the acceleration pulses corresponding to the velocities $30 \mathrm{~km} / \mathrm{h}$ and $50 \mathrm{~km} / \mathrm{h}$ (Vezin et al., 2002) defined on the COG of a rigid seat. The sled tests were performed for two velocities using two safety systems (airbag and nanobag). The test matrix can be summarized as follows:

- two velocities $(30 \mathrm{~km} / \mathrm{h}$ and $50 \mathrm{~km} / \mathrm{h})$,

- 15 occupant anthropometries (according to Table 1),

- two safety approaches (airbag and nanobag),

where the nanobag was tested for 4, 6, 8 and 10 layers of LLDPE forming the nanobag, i.e. $2 \times 15 \times 5=150$ configurations in total. Figure 3 shows the a particular initial configurations for the airbag and the nanobag in case of the P50 male, age range 25$30 \mathrm{YO}$, height equals to $178 \mathrm{~cm}$ and weight equals to $78 \mathrm{~kg}$. 

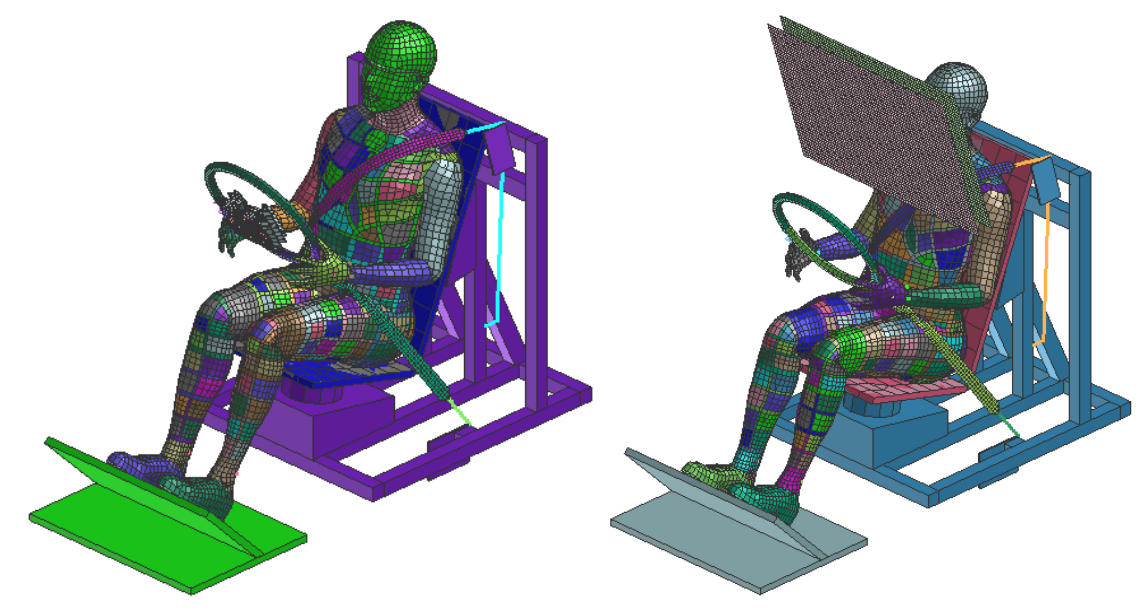

Figure 3: The sled test initial configurations. The airbag (left) and the nanobag (right).

\section{Results and discussion}

This study is virtually assessing the new safety technology called nanobag with respect to the airbag. This feature consists of the rigid frame and thin elastic foil. Such technology can help in safety of the future cars (where the non-standard seating configurations are being considered - i.e. autonomous car). The identified material model of the LLDPE foil was used to develop the nanobag safety system and its safety performance was assessed and compared to the traditional airbag by the numerical simulations using previously validated biomechanical virtual human body model.

Since the most vulnerable human parts in case of frontal crashes are the head and the neck respectively, their injury indicators (criteria) are considered as main assessment criteria for the nanobag safety system. The head injury risk is evaluated with the head injury criteria (HIC) (Schmitt et al.), brain criteria (BrIC and UBrIC) for soft tissue injury (Gabler, 2018; 2019; Sahoo, 2020) and neck injury is tested via neck injury criteria (Nij), (Schmitt et al., 2013, Wheeler et al., 1998). The head acceleration curves are filtered with the CFC 1000 filter, and HIC is calculated from such filtered curves. In order to assess the performance of the nanobag with respect to traditional airbag, the additional probability of AIS injury for head and brain injury were also considered, (Schmitt et al., 
2013). The UBrIC criterion for predicting brain injury (soft tissue) is based on the response of the second-order mechanical system, and relates rotational head kinematics to strain-based brain injury. It was developed based on the maximum principal strain (MPS) or cumulative strain damage measure (CSDM) and it can be evaluated with respect to these matrices. The Nij criterion considers the axial force and bending moment generated on the neck spine, and plots them into the corridors, that depend also on the anthropometry of the particular passenger and its anthropometry.

Consequently, the HIC and maximum Nij criteria result in a single scalar value, that can be formulated with the injury risk. These values can be recalculated by utilising the S-Shape curve to obtain the probability of particular injury risk in terms of Abbreviated Injury Scale (AIS) value. The contact force between occupant and particular SRS is also monitored and the maximum values are presented.

\section{$30 \mathrm{~km} / \mathrm{h}$ results}

Head acceleration results in the time dependence curve of its COG versus time. The plot on Figure 4 shows the limits (maximum and minimum values) of all the configurations as well as its mean value. This plot shows that all the cases have similar curve shape, and there is not a one curve, which would behave in very different manner. 


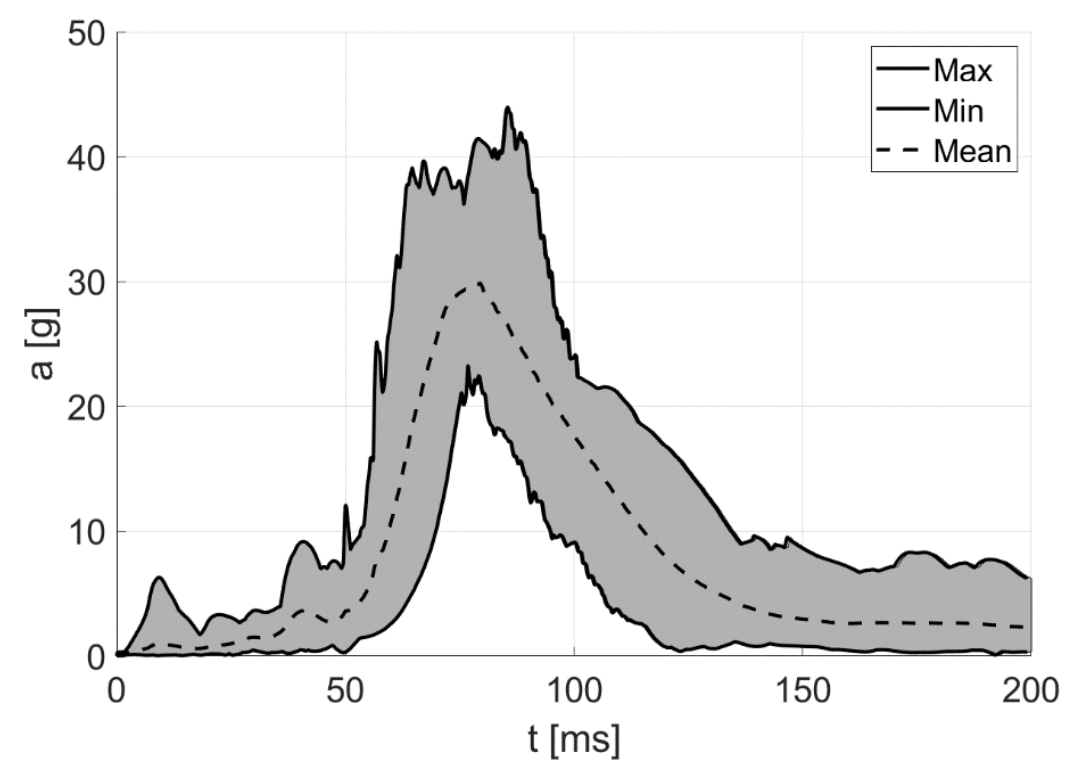

Figure 4: Head COG acceleration for $30 \mathrm{~km} / \mathrm{h}$ pulse

In order to assess the effect of the airbag and nanobag for a various anthropometry, respectively, the plot of Body Mass Index (BMI) vs. Head Injury Criterion (HIC) are depicted. The BMI pairs the height and weight of the subject, and both are considered to be assessed for the safety effect, see Figure 5. All the curves report increasing of the HIC value for higher BMI for both safety systems. The approximation curve is the lowest in case of airbag, followed by 4 layers nanobag. With the increasing number of layers, the HIC values tend to increase (more layers, stiffer obstacle and higher head acceleration). However, all values are still within the acceptable region of head injury risk $<1000$ (Hobbs, C.A. et al, 1998). The best protection is predicted for standard airbag for BMI up to 29. After this limit, the HIC predicts lower value for nanobag with 4 layers. 


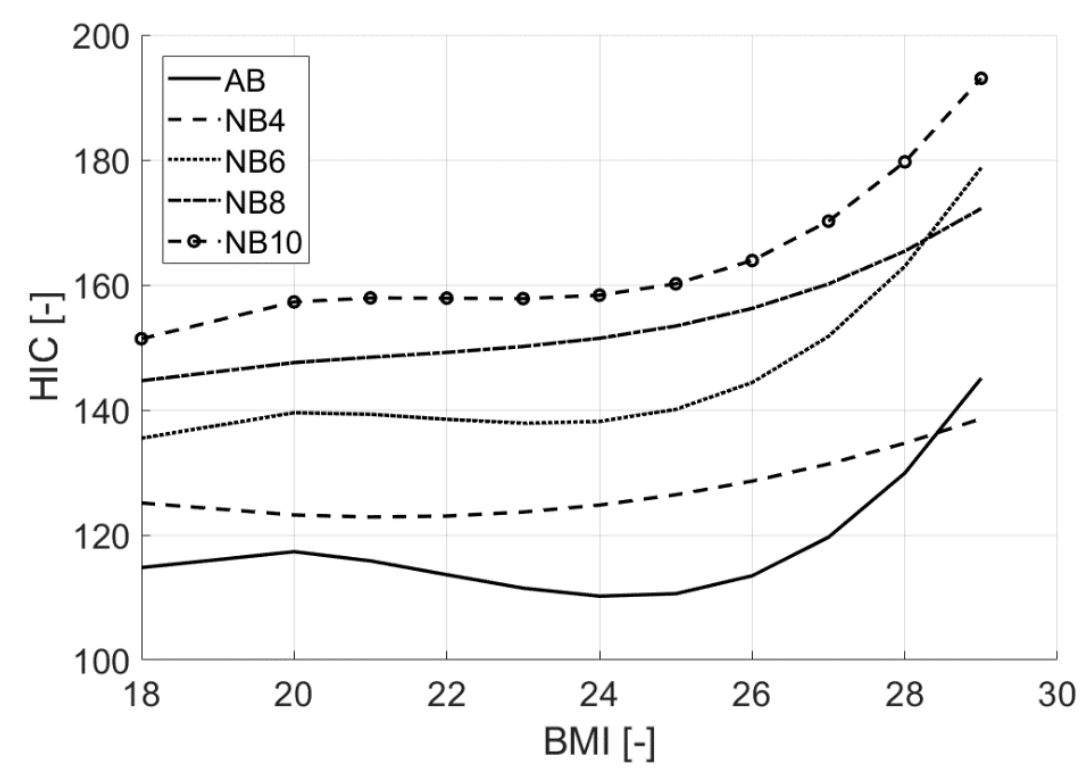

Figure 5: BMI vs HIC plots for $30 \mathrm{~km} / \mathrm{h}$ pulse

Neck injury risk is tested by means of the Nij criterion, that plots the axial compression force depending on the bending moment into the corridor (function of the antopometry). If the curves are inside the corridor, the risk of neck injury is within the safety limits and no serious injury should appear. The Nij criterion curves lay inside the defined corridors in all tested scenarios for the acceleration pulse of $30 \mathrm{~km} / \mathrm{h}$.

The full results are displayed in Table 2, where the HIC value, the Nij max value, probability of AIS injury 2 for head and 2-5 for the neck, BrIC, UBrIC criteria and maximum contact force $F_{c}$ between passenger and SRS (airbag and nanobag), respectively, are displayed. The last three lines (79-81) in the Table 2 show maximum, minimum and average of the particular values. 
Particular subjects (VH) are represented as males ( $\mathrm{Ma}$ ) and females $(\mathrm{Fa})$ of given age (a) and percentile $(p)$. Airbag $(A B)$ and nanobag NBn of n layers are compared.

Table 2: Results of $30 \mathrm{~km} / \mathrm{h}$ impact pulse

\begin{tabular}{|c|c|c|c|c|c|c|c|c|c|c|c|c|c|c|c|}
\hline \multirow{2}{*}{ VH } & \multirow{2}{*}{ m [kg] } & \multirow{2}{*}{$\mathrm{h}[\mathrm{cm}]$} & \multirow{2}{*}{ BMI } & \multirow{2}{*}{ SRS } & \multirow{2}{*}{ HIC } & \multirow{2}{*}{$\mathrm{Nij}$} & \multirow{2}{*}{$\begin{array}{l}\text { Head } \\
\text { AIS2+ }\end{array}$} & \multicolumn{4}{|c|}{ Neck } & \multirow{2}{*}{ BrIC } & \multicolumn{2}{|c|}{ UBrIC } & \multirow{2}{*}{$\mathrm{Fc}[\mathrm{kN}]$} \\
\hline & & & & & & & & AlS2+ & AIS3+ & AIS4+ & AIS5+ & & MPS & CSDM & \\
\hline \multirow{5}{*}{$\begin{array}{l}\text { M14 } \\
\text { p50 }\end{array}$} & 57 & 170 & 20 & $A B$ & 126 & 0.13 & 1.69 & 13.08 & 4.91 & 7.36 & 2.52 & 0.57 & 0.19 & 0.28 & 1.37 \\
\hline & 57 & 170 & 20 & NB4 & 113 & 0.071 & 1.22 & 12.24 & 4.36 & 6.86 & 2.34 & 0.50 & 0.17 & 0.24 & 0.46 \\
\hline & 57 & 170 & 20 & NB6 & 125 & 0.061 & 1.67 & 12.12 & 4.28 & 6.79 & 2.31 & 0.49 & 0.17 & 0.24 & 0.64 \\
\hline & 57 & 170 & 20 & NB8 & 135 & 0.061 & 2.06 & 12.12 & 4.28 & 6.79 & 2.31 & 0.48 & 0.16 & 0.23 & 0.73 \\
\hline & 57 & 170 & 20 & NB10 & 145 & 0.051 & 2.55 & 11.99 & 4.20 & 6.71 & 2.28 & 0.47 & 0.16 & 0.22 & 0.79 \\
\hline \multirow{5}{*}{$\begin{array}{l}\text { M14 } \\
\text { p95 }\end{array}$} & 70 & 180 & 22 & $A B$ & 95 & 0.099 & 0.69 & 12.62 & 4.60 & 7.08 & 2.42 & 0.64 & 0.23 & 0.32 & 1.41 \\
\hline & 70 & 180 & 22 & NB4 & 110 & 0.057 & 1.11 & 12.06 & 4.25 & 6.75 & 2.30 & 0.50 & 0.17 & 0.24 & 0.49 \\
\hline & 70 & 180 & 22 & NB6 & 128 & 0.05 & 1.78 & 11.98 & 4.19 & 6.70 & 2.28 & 0.53 & 0.18 & 0.26 & 0.64 \\
\hline & 70 & 180 & 22 & NB8 & 135 & 0.045 & 2.10 & 11.91 & 4.15 & 6.66 & 2.27 & 0.51 & 0.18 & 0.25 & 0.76 \\
\hline & 70 & 180 & 22 & NB10 & 143 & 0.039 & 2.46 & 11.84 & 4.11 & 6.62 & 2.25 & 0.50 & 0.17 & 0.24 & 0.83 \\
\hline \multirow{5}{*}{$\begin{array}{l}\text { F14 } \\
\text { p05 }\end{array}$} & 41 & 153 & 18 & $A B$ & 108 & 0.23 & 1.06 & 14.45 & 5.88 & 8.18 & 2.82 & 0.50 & 0.17 & 0.24 & 0.90 \\
\hline & 41 & 153 & 18 & NB4 & 126 & 0.13 & 1.69 & 13.05 & 4.89 & 7.34 & 2.51 & 0.49 & 0.16 & 0.23 & 0.39 \\
\hline & 41 & 153 & 18 & NB6 & 138 & 0.11 & 2.20 & 12.79 & 4.72 & 7.18 & 2.45 & 0.48 & 0.16 & 0.23 & 0.48 \\
\hline & 41 & 153 & 18 & NB8 & 145 & 0.097 & 2.56 & 12.59 & 4.58 & 7.06 & 2.41 & 0.47 & 0.15 & 0.22 & 0.54 \\
\hline & 41 & 153 & 18 & NB10 & 153 & 0.086 & 2.92 & 12.44 & 4.49 & 6.98 & 2.38 & 0.46 & 0.15 & 0.22 & 0.63 \\
\hline \multirow{5}{*}{$\begin{array}{l}\text { M28 } \\
\text { p50 }\end{array}$} & 76 & 178 & 24 & $A B$ & 91 & 0.14 & 0.59 & 13.22 & 5.01 & 7.44 & 2.55 & 0.63 & 0.22 & 0.31 & 0.10 \\
\hline & 76 & 178 & 24 & NB4 & 100 & 0.09 & 0.81 & 12.49 & 4.52 & 7.00 & 2.39 & 0.51 & 0.17 & 0.24 & 0.45 \\
\hline & 76 & 178 & 24 & NB6 & 108 & 0.077 & 1.06 & 12.33 & 4.42 & 6.91 & 2.36 & 0.50 & 0.17 & 0.24 & 0.62 \\
\hline & 76 & 178 & 24 & NB8 & 116 & 0.069 & 1.33 & 12.22 & 4.35 & 6.84 & 2.33 & 0.49 & 0.16 & 0.24 & 0.74 \\
\hline & 76 & 178 & 24 & NB10 & 124 & 0.066 & 1.62 & 12.18 & 4.32 & 6.82 & 2.32 & 0.49 & 0.16 & 0.23 & 0.81 \\
\hline \multirow{5}{*}{$\begin{array}{l}\text { M28 } \\
\text { p95 }\end{array}$} & 94 & 187 & 27 & $A B$ & 95 & 0.11 & 0.68 & 12.82 & 4.73 & 7.20 & 2.46 & 0.73 & 0.26 & 0.36 & 2.16 \\
\hline & 94 & 187 & 27 & NB4 & 112 & 0.069 & 1.20 & 12.23 & 4.35 & 6.85 & 2.33 & 0.51 & 0.17 & 0.25 & 0.54 \\
\hline & 94 & 187 & 27 & NB6 & 127 & 0.055 & 1.75 & 12.04 & 4.23 & 6.74 & 2.29 & 0.52 & 0.18 & 0.25 & 0.71 \\
\hline & 94 & 187 & 27 & NB8 & 141 & 0.049 & 2.37 & 11.97 & 4.19 & 6.70 & 2.28 & 0.52 & 0.18 & 0.25 & 0.86 \\
\hline & 94 & 187 & 27 & NB10 & 153 & 0.045 & 2.93 & 11.92 & 4.16 & 6.67 & 2.27 & 0.50 & 0.17 & 0.25 & 1.00 \\
\hline \multirow{5}{*}{$\begin{array}{l}\text { F28 } \\
\text { p05 }\end{array}$} & 53 & 158 & 21 & $A B$ & 125 & 0.21 & 1.67 & 14.17 & 5.68 & 8.02 & 2.75 & 0.47 & 0.16 & 0.22 & 1.17 \\
\hline & 53 & 158 & 21 & NB4 & 137 & 0.13 & 2.18 & 12.96 & 4.83 & 7.29 & 2.49 & 0.48 & 0.16 & 0.23 & 0.47 \\
\hline & 53 & 158 & 21 & NB6 & 152 & 0.095 & 2.90 & 12.56 & 4.56 & 7.05 & 2.40 & 0.46 & 0.15 & 0.22 & 0.67 \\
\hline & 53 & 158 & 21 & NB8 & 164 & 0.077 & 3.53 & 12.32 & 4.41 & 6.90 & 2.35 & 0.45 & 0.15 & 0.21 & 0.80 \\
\hline & 53 & 158 & 21 & NB10 & 173 & 0.072 & 4.05 & 12.26 & 4.37 & 6.87 & 2.34 & 0.43 & 0.14 & 0.21 & 0.88 \\
\hline \multirow{5}{*}{$\begin{array}{l}\text { M44 } \\
\text { p50 }\end{array}$} & 79 & 174 & 26 & $A B$ & 117 & 0.16 & 1.36 & 13.38 & 5.12 & 7.54 & 2.58 & 0.72 & 0.26 & 0.36 & 1.64 \\
\hline & 79 & 174 & 26 & NB4 & 125 & 0.087 & 1.66 & 12.46 & 4.50 & 6.99 & 2.38 & 0.57 & 0.20 & 0.28 & 0.47 \\
\hline & 79 & 174 & 26 & NB6 & 140 & 0.068 & 2.33 & 12.21 & 4.34 & 6.84 & 2.33 & 0.62 & 0.22 & 0.31 & 0.64 \\
\hline & 79 & 174 & 26 & NB8 & 151 & 0.058 & 2.86 & 12.08 & 4.26 & 6.76 & 2.30 & 0.63 & 0.23 & 0.31 & 0.84 \\
\hline & 79 & 174 & 26 & NB10 & 162 & 0.049 & 3.44 & 11.97 & 4.19 & 6.70 & 2.28 & 0.64 & 0.23 & 0.32 & 0.94 \\
\hline \multirow{5}{*}{$\begin{array}{l}\text { M44 } \\
\text { p95 }\end{array}$} & 96 & 186 & 28 & $A B$ & 144 & 0.14 & 2.48 & 13.18 & 4.98 & 7.42 & 2.54 & 0.71 & 0.24 & 0.34 & 2.16 \\
\hline & 96 & 186 & 28 & NB4 & 114 & 0.087 & 1.24 & 12.45 & 4.49 & 6.98 & 2.38 & 0.65 & 0.23 & 0.32 & 0.51 \\
\hline & 96 & 186 & 28 & NB6 & 132 & 0.078 & 1.96 & 12.34 & 4.42 & 6.91 & 2.36 & 0.56 & 0.19 & 0.27 & 0.68 \\
\hline & 96 & 186 & 28 & NB8 & 141 & 0.063 & 2.36 & 12.15 & 4.30 & 6.80 & 2.32 & 0.55 & 0.19 & 0.27 & 0.83 \\
\hline & 96 & 186 & 28 & NB10 & 145 & 0.059 & 2.55 & 12.10 & 4.27 & 6.77 & 2.31 & 0.71 & 0.26 & 0.36 & 0.97 \\
\hline
\end{tabular}






The maximum value of the HIC is 214 (M, P95, $54 \mathrm{YO}, 184 \mathrm{~cm}, 96 \mathrm{~kg}$ for 6 layers nanobag) and its minimum is 91 (M, P50, $28 \mathrm{YO}, 178 \mathrm{~cm}, 76 \mathrm{~kg}$, airbag). The results of the crash scenario with no safety features (seat belts only) for average occupant (M P50, $28 \mathrm{YO}, 178 \mathrm{~cm}, 76 \mathrm{~kg}$ ) are also provided in Table 2 (line 78) to get a referenced value for 
no SRS configuration. The maximum probability of AIS $2+$ for head and neck are $6.7 \%$ and $14.7 \%$, respectively. Criteria for soft tissue brain injury (BrIC and UBrIC) do not have specific thresholds to distinguish the particular injury risk. However, they can be used to assess performance of nanobag, comparing to traditional airbag. BrIC results with the minimum value 0.4 (F P05, $44 \mathrm{YO}, 154 \mathrm{~cm}, 53 \mathrm{~kg}$ - airbag) and with the maximum 0.9 (M P95, 64 YO, $180 \mathrm{~cm}, 95 \mathrm{~kg}$ - airbag). Generally, the BrIC gives slightly higher values for the particular anthropometry in configuration with the airbag, but the range of these values is not very large. Criterion UBrIC has its minimum MPS value 0.14 (F P05, 28 YO, $158 \mathrm{~cm}, 53 \mathrm{~kg}$ - nanobag 10 layers; F P05, $44 \mathrm{YO}, 154 \mathrm{~cm}, 53 \mathrm{~kg}$ - airbag and nanobag 10 layers; F P05, 54 YO, $154 \mathrm{~cm}, 55 \mathrm{~kg}$ - airbag) and the minimum CSDM value 0.2 (F P05, 44 YO, $154 \mathrm{~cm}, 53 \mathrm{~kg}$ - airbag, F P05, 54 YO, $154 \mathrm{~cm}, 55 \mathrm{~kg}$ - airbag), while the maximum MPS value is 0.33 (M P95, $64 \mathrm{YO}, 180 \mathrm{~cm}, 95 \mathrm{~kg}$ - airbag) and maximum in CSDM is 0.45 (M P95, $64 \mathrm{YO}, 180 \mathrm{~cm}, 95 \mathrm{~kg}$ - airbag). The UBrIC criterion results in very similar values for the specific anthropometry, however, the maximal values for MPS and CSDM are predicted for the airbag. The minimum contact force is $0.1 \mathrm{kN}$ (M P50, $28 \mathrm{YO}, 178 \mathrm{~cm}, 76 \mathrm{~kg}$ - airbag) and maximum value $2.3 \mathrm{kN}$ (M P95, $54 \mathrm{YO}, 184 \mathrm{~cm}, 96$ $\mathrm{kg}$ - airbag). The minimum value is for average male (the size of P50 dummy) with the airbag SRS. Such results confirmed that the passive safety technologies (seat belts and airbag) are optimized for this anthropometry. The Table 3 summarises the minimum, maximum and average values for the particular criteria, together with the anthropometry and SRS. Appendix

Table 3: Summary of the extreme values of the particular criteria for $30 \mathrm{~km} / \mathrm{h}$

\begin{tabular}{|c|c|c|c|c|c|c|c|}
\hline Criteria & \multicolumn{3}{|c|}{ Min } & \multicolumn{3}{c|}{ Max } & Average \\
\hline & Value & Anthropometry & SRS & Value & Anthropometry & SRS & \\
\hline HIC & 91 & M P50, 28 YO, 178 cm, 76 kg & AB & 214 & M P95, 54 YO, 184 cm, 96 kg & NB6 & 144 \\
\hline
\end{tabular}




\begin{tabular}{|c|c|c|c|c|c|c|c|}
\hline Nij & 0.039 & М P95, 14 YO, $180 \mathrm{~cm}, 70 \mathrm{~kg}$ & NB10 & 0.24 & $\mathrm{~F} P 05,64 \mathrm{YO}, 150 \mathrm{~cm}, 60 \mathrm{~kg}$ & $\mathrm{AB}$ & 0.1 \\
\hline BrIC & 0.4 & F P05, $44 \mathrm{YO}, 154 \mathrm{~cm}, 53 \mathrm{~kg}$ & $\mathrm{AB}$ & 0.9 & M P95, $64 \mathrm{YO}, 180 \mathrm{~cm}, 95 \mathrm{~kg}$ & $\mathrm{AB}$ & 0.58 \\
\hline \multirow{3}{*}{ UBrIC - MPS } & \multirow{3}{*}{0.14} & $\mathrm{FP} 05,28 \mathrm{YO}, 158 \mathrm{~cm}, 53 \mathrm{~kg}$ & NB10 & \multirow{3}{*}{0.33} & \multirow{3}{*}{ M P95, 64 YO, $180 \mathrm{~cm}, 95 \mathrm{~kg}$} & \multirow{3}{*}{$\mathrm{AB}$} & \multirow{3}{*}{0.2} \\
\hline & & $\mathrm{F}$ P $05,44 \mathrm{YO}, 154 \mathrm{~cm}, 53 \mathrm{~kg}$ & $\mathrm{AB} \& \mathrm{NB} 10$ & & & & \\
\hline & & $\mathrm{F}$ P05, 54 YO, $154 \mathrm{~cm}, 55 \mathrm{~kg}$ & $\mathrm{AB}$ & & & & \\
\hline UBrIC - CSDM & 0.2 & F P05, $44 \mathrm{YO}, 154 \mathrm{~cm}, 53 \mathrm{~kg}$ & $\mathrm{AB}$ & 0.45 & M P95, 64 YO, $180 \mathrm{~cm}, 95 \mathrm{~kg}$ & $\mathrm{AB}$ & 0.28 \\
\hline $\mathrm{Fc}[\mathrm{kN}]$ & 0.1 & M P50, 28 YO, $178 \mathrm{~cm}, 76 \mathrm{~kg}$ & $\mathrm{AB}$ & 2.3 & M P95, 54 YO, $184 \mathrm{~cm}, 96 \mathrm{~kg}$ & $\mathrm{AB}$ & 0.88 \\
\hline
\end{tabular}

The results suggest that head and neck injury risks for all safety measures are in the acceptable range and predicts similar safety performance of nanobag and airbag in this specific crash configuration. The majority of the max values occurs for the Airbag. However, the airbag SRS offers also majority of the minimal values.

\section{$50 \mathrm{~km} / \mathrm{h}$ results}

The head acceleration curves (corridors of max and min values; and average curve) are plotted at the Figure 6. There is a significant peak of the acceleration about the time of $700 \mathrm{~ms}$, with the peak value about $135 \mathrm{~g}$. These are curves of Male, P95 percentile, $54 \mathrm{YO}, 184 \mathrm{~cm}, 96 \mathrm{~kg}$. Such values are higher than the rest of the curves, however the HIC criterion are still lower than critical threshold of 1000 (here the max value is 702 for the 10 layers nanobag). The peak is caused by the internal structure of the Virthuman, where the neck vertebrae reaches their defined physiological limit and stops the head forward motion. 


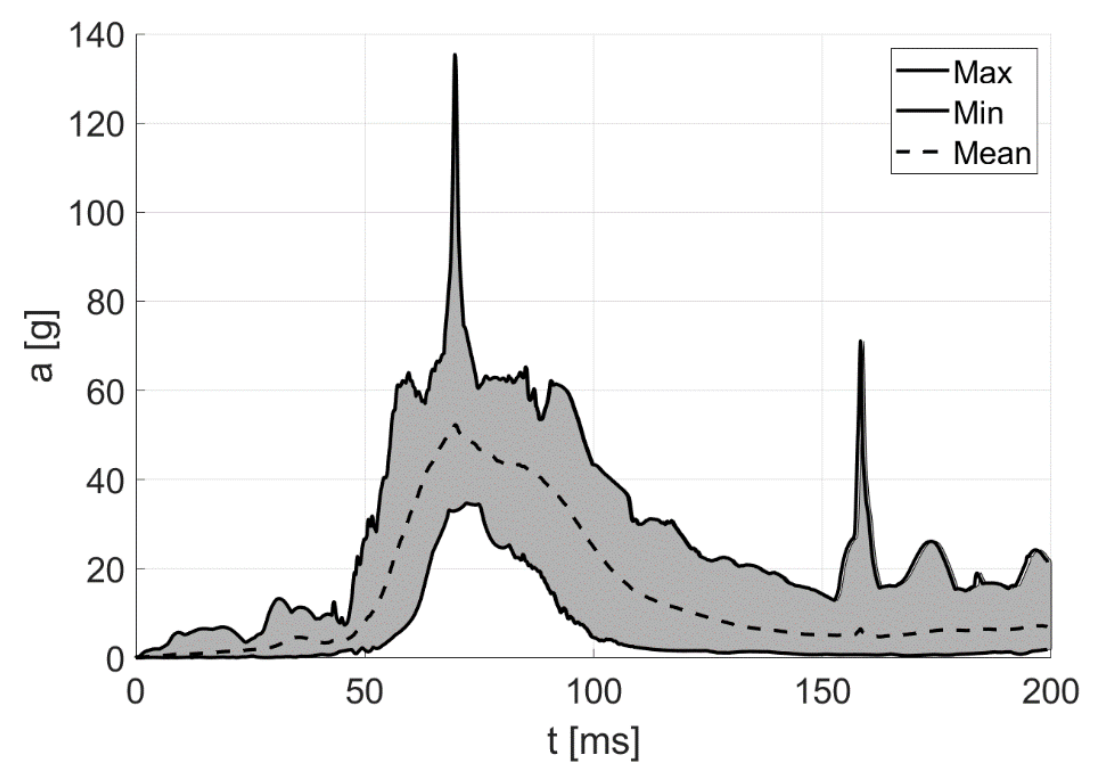

Figure 6: Head COG acceleration for $50 \mathrm{~km} / \mathrm{h}$ pulse

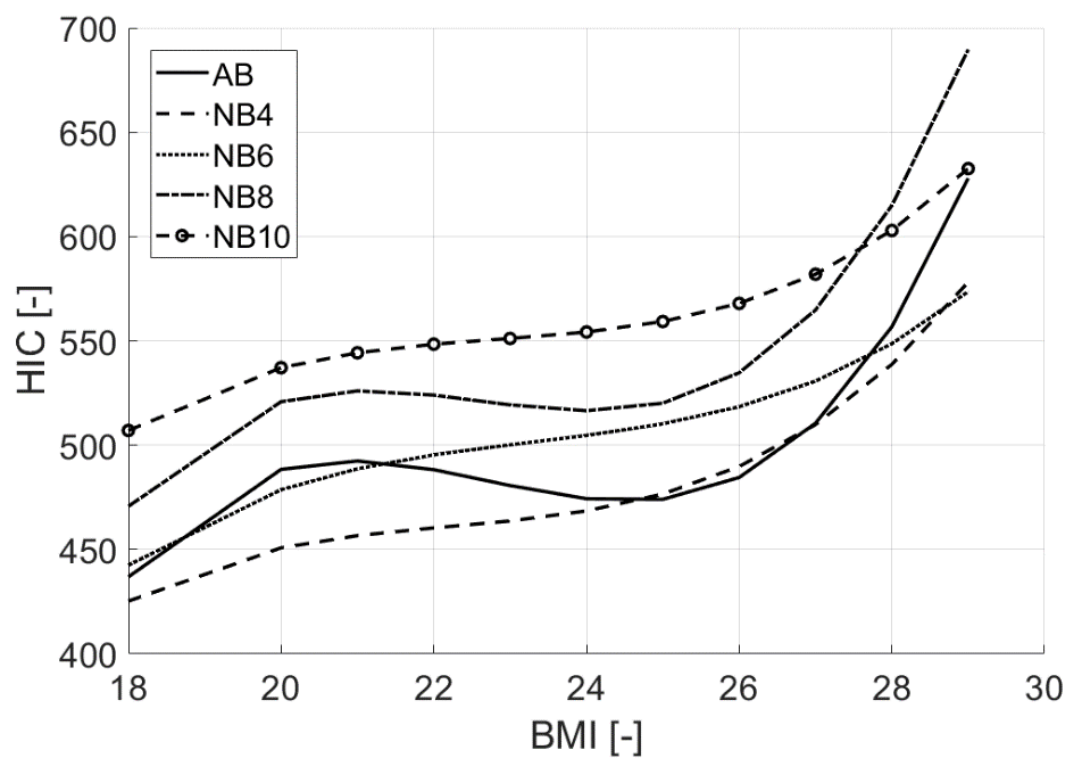

Figure 7: BMI vs HIC plots for $50 \mathrm{~km} / \mathrm{h}$ pulse

The curves of BMI vs. HIC have a similar trend to the $30 \mathrm{~km} / \mathrm{h}$ pulse. However, there is an interesting effect of the higher impact velocity. The approximation curve (mean value) does not significantly increase with the increasing number of LLDPE layers, , see Figure 7. The best protection of the head is achieved by application of four layer 
nanobag. These results suggest that in a higher impact velocity, the difference between standard airbag and nanobag is lower than in a slow velocity impact.

The Nij curves are significantly higher than in case of $30 \mathrm{~km} / \mathrm{h}$, however they still lay inside the corridors. There is only one configuration, where the curves cross the corridors (M, P95, $54 \mathrm{YO}, 184 \mathrm{~cm}, 95 \mathrm{~kg}$ ), see Figure 8, where also results of the Male, P50, $28 \mathrm{YO}, 178 \mathrm{~cm}, 76 \mathrm{~kg}$ (standard dummy size) are plotted as a reference.


Figure 8: Nij criterion for average Male, P50, 28 YO, $178 \mathrm{~cm}, 76 \mathrm{~kg}$ (left) and Male, P95, 54 YO, $184 \mathrm{~cm}, 95 \mathrm{~kg}$ (right)

The full results table are displayed in Table 4, where the HIC value, the Nij max value, probability of AIS injury 2 for head and 2-5 for the neck, BrIC, UBrIC criteria and maximum contact force Fc between passenger and SRS (airbag and nanobag), respectively, are displayed. The last three lines (79-81) in the Table 4 show maximum, minimum and average of the particular values. 
Particular subjects $(V H)$ are represented as males $(M)$ and females $(F)$ of given percentile $(P)$.

Airbag $(A B)$ and nanobag NBn of n layers are compared.

Table 4: Results of $50 \mathrm{~km} / \mathrm{h}$ impact pulse

\begin{tabular}{|c|c|c|c|c|c|c|c|c|c|c|c|c|c|c|c|}
\hline \multirow{2}{*}{ VH } & \multirow{2}{*}{ m [kg] } & \multirow{2}{*}{$\mathrm{h}[\mathrm{cm}]$} & \multirow{2}{*}{ BMI } & \multirow{2}{*}{ RS } & \multirow{2}{*}{ HIC } & \multirow{2}{*}{ Nij } & \multirow{2}{*}{$\begin{array}{l}\text { Head } \\
\text { AIS2+ }\end{array}$} & \multicolumn{4}{|c|}{ Neck } & \multirow{2}{*}{ BrIC } & \multicolumn{2}{|c|}{ UBrIC } & \multirow[t]{2}{*}{$c l k n$} \\
\hline & & & & & & & & AIS2+ & 153+ & AIS4+ & AIS5+ & & MPS & CSDM & \\
\hline \multirow{5}{*}{$\begin{array}{c}\text { M14 } \\
\text { p50 }\end{array}$} & 57 & 170 & 20 & $A B$ & 493 & 0.21 & 26.59 & 14.13 & 5.65 & 7.99 & 2.75 & 0.72 & 0.24 & 35 & \\
\hline & 57 & 170 & 20 & NB4 & b9 & .12 & 1.26 & 12.87 & 4.77 & 7.23 & 2.47 & 0.60 & .20 & .29 & \\
\hline & 57 & 170 & 20 & NB6 & 428 & 0.11 & 22.57 & 12.70 & 4.66 & 7.13 & 2.44 & 0.58 & 0.19 & 28 & 0.95 \\
\hline & 57 & 170 & 20 & NB8 & 456 & 0.09 & 24.36 & 12.52 & 4.54 & 7.02 & 2.40 & 0.60 & 0.20 & 9 & 16 \\
\hline & 57 & 70 & 20 & NB10 & & 08 & .59 & 12.34 & 4.42 & .92 & 36 & 61 & .21 & & 36 \\
\hline \multirow{5}{*}{$\begin{array}{l}\text { M14 } \\
\text { p95 }\end{array}$} & 70 & 80 & 22 & $A B$ & 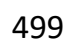 & 16 & .90 & 13.40 & & .55 & .59 & 96 & .35 & & 49 \\
\hline & 70 & 180 & 22 & NB4 & 460 & 0.12 & 24.58 & 12.84 & 4.75 & 7.21 & 2.46 & 0.62 & 0.20 & 0.30 & 67 \\
\hline & 70 & 180 & 22 & NB6 & 495 & 0.10 & 26.67 & 12.59 & 4.59 & 7.07 & 2.41 & 0.58 & 0.19 & 0.28 & 0.89 \\
\hline & 70 & 180 & 22 & NB8 & 541 & 0.08 & 29.14 & 12.39 & & 6.95 & 2.37 & 0.71 & 0.25 & & 13 \\
\hline & 70 & 180 & 22 & NB10 & & 7 & .78 & .29 & & 9 & 5 & 9 & 29 & & 32 \\
\hline \multirow{5}{*}{$\begin{array}{l}\text { F14 } \\
\text { p05 }\end{array}$} & 41 & 53 & 18 & $A B$ & 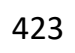 & .33 & 2.24 & 16.02 & 7. & .15 & 17 & 0.57 & .19 & & 99 \\
\hline & 41 & 153 & 18 & NB4 & 419 & 0.20 & 1.96 & 14.07 & 5.60 & 7.95 & 2.73 & 0.61 & 0.20 & 0.29 & 0.56 \\
\hline & 41 & 153 & 18 & NB6 & 440 & 0.16 & 23.34 & 13.48 & 5.18 & 7.60 & 2.60 & 0.57 & 0.19 & 0.27 & 0.79 \\
\hline & 41 & 53 & 18 & NB8 & 76 & 0.12 & 25.59 & 12.86 & 4.76 & 7.22 & 2.47 & 0.54 & 0.18 & .26 & .96 \\
\hline & 41 & & 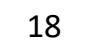 & Te & & 8 & 43 & 39 & & 5 & 7 & & 17 & & 15 \\
\hline \multirow{5}{*}{$\begin{array}{l}\text { M28 } \\
\text { p50 }\end{array}$} & 76 & 78 & 24 & $A E$ & 45 & 0.23 & 1.10 & 14.49 & 5.9 & 8.21 & 2.82 & 1.02 & 0.37 & 1 & 12 \\
\hline & 76 & 78 & 24 & NB4 & 496 & 0.17 & .77 & 13.64 & 5. & 7.69 & .64 & 0.63 & 0.21 & & 0.79 \\
\hline & 76 & 178 & 24 & NB6 & 519 & 0.16 & 28.02 & 13.40 & 5.13 & 7.55 & 2.58 & 0.59 & 0.20 & .29 & 1.02 \\
\hline & 76 & 8 & 24 & NB8 & 541 & 0.14 & 9.18 & 13.20 & 4.9 & 7.43 & .54 & .58 & 20 & 8 & .27 \\
\hline & 76 & 17 & 24 & NB1 & & 3 & 9 & 7 & & 7.29 & 9 & 2 & 2 & & 51 \\
\hline \multirow{5}{*}{$\begin{array}{c}\text { M28 } \\
\text { p95 }\end{array}$} & 92 & & 27 & $A B$ & & 0.19 & 51 & 13.92 & 5. & 7.87 & 0 & 1 & & & .41 \\
\hline & 94 &  & 27 & NB4 & 541 & 0.18 & 29.14 & 13.74 & 5.37 & 7.75 & 2.66 & 0.84 & 0.28 & 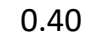 & 1.00 \\
\hline & 94 & 187 & 27 & NB6 & 505 & 0.16 & 27.24 & 13.42 & 5.14 & 7.56 & 2.59 & 0.93 & 0.32 & 6 & 0.99 \\
\hline & 92 & & 27 & NB8 & 45 & 0.14 & 26.91 & 13.10 & 4. & 7.3 & 2 & 64 & 22 & & 44 \\
\hline & 92 & 107 & 7 & NB10 & 7 & 3 & 91 & 98 & 4.85 & 0 & 0 & 2 & 25 & 6 & .70 \\
\hline \multirow{5}{*}{$\begin{array}{l}\text { F28 } \\
\text { p05 }\end{array}$} & 5 & & & & & & & & & 4 & & & & & 42 \\
\hline & 53 & 1 & 21 & NB4 & $5 / 1$ & 0.27 & 30.59 & 15.07 & 6.35 & 8.56 & 2.95 & 0.71 & 0.23 & 35 & 0.63 \\
\hline & 53 & 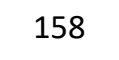 & 21 & NB6 & 600 & 0.22 & 31.89 & 14.31 & 5.78 & 8.10 & 2.79 & 0.67 & 0.22 & 4 & .93 \\
\hline & 53 & & 21 & NB8 & 6 & 0.18 & 2.69 & 13.67 & 5.32 & 7.71 & .64 & .65 & 0.21 & 3 & .17 \\
\hline & 53 & & 21 & NB10 & 643 & 0.16 & 33.58 & 13.42 & 4 & 7.56 & 9 & 64 & 21 & 2 & .38 \\
\hline \multirow{5}{*}{ p50 } & 7 & & & & & & .70 & & & & & 3 & 33 & & 79 \\
\hline & 79 & 174 & 26 & NB4 & 475 & 0.15 & 25.53 & 13.36 & 5.10 & 7.53 & 58 & .65 & 0.22 & 2 & 0.70 \\
\hline & 79 & & 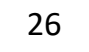 & NB6 & 50 & 0.13 & 7.33 & 13.09 & & 7.36 & & 0.62 & 21 & & 1.00 \\
\hline & 79 & & 26 & B8 & 545 & 0.11 & 29.36 & 12.74 & 4.68 & 7.15 & 2.44 & 0.67 & 0.24 & 3 & 1.29 \\
\hline & 79 & & 26 & NB10 & 577 & 0.09 & 30.88 & 12.45 & & 6.98 & & 0.75 & 27 & .37 & 1.57 \\
\hline \multirow{5}{*}{$\begin{array}{l}\text { IV44 } \\
\text { p95 }\end{array}$} & 9 & & 28 & & 56 & 4 & 13 & 88 & 5.9 & 8.27 & 4 & 0.89 & 0.31 & $T$ & 3.34 \\
\hline & 96 & 186 & 28 & NB4 & 624 & 0.17 & 32.87 & 13.64 & 5.30 & 7.70 & 2.64 & 0.80 & 0.26 & 39 & 0.82 \\
\hline & 96 & 186 & 28 & NB6 & 500 & 0.14 & 26.98 & 13.11 & 4.93 & 7.38 & 2.52 & 0.64 & 0.21 & 0.31 & 1.09 \\
\hline & 96 & & 28 & NB8 & 61 & 0.17 & 32.68 & 13.52 & 5.2 & 7.62 & 2.61 & 0.77 & 0.26 & 0.37 & 1.30 \\
\hline & Ju & 100 & 20 & NB10 & 030 & 0.16 & 33.32 & 13.46 & 5.17 & 7.58 & 2.60 & 0.76 & 0.26 & 0.37 & 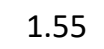 \\
\hline
\end{tabular}




\begin{tabular}{|c|c|c|c|c|c|c|c|c|c|c|c|c|c|c|c|}
\hline \multirow{4}{*}{$\begin{array}{l}\text { F44 } \\
\text { p05 }\end{array}$} & 53 & 154 & 22 & $A B$ & 453 & 0.39 & 24.14 & 16.95 & 7.86 & .72 & 3.38 & .63 & 0.22 & I & 10 \\
\hline & 53 & 154 & 22 & NB4 & 448 & 0.26 & 23.85 & 14.82 & 6.16 & 8.41 & 2.90 & 0.64 & 0.21 & 0.31 & 0.63 \\
\hline & 3 & 154 & 22 & NB6 & 476 & 0.20 & 25.61 & 14.04 & 5.58 & 7.94 & 2.73 & 0.61 & 0.20 & 0.29 & 0.85 \\
\hline & 53 & 154 & 22 & NB8 & 513 & 0.16 & 27.70 & 13.46 & 5.17 & 7.58 & 2.60 & 0.58 & 0.19 & 0.28 & 1.09 \\
\hline \multirow{7}{*}{$\begin{array}{c}\text { M54 } \\
\text { p50 }\end{array}$} & 53 & 154 & 22 & NB10 & 542 & 0.14 & 29.22 & 13.10 & 4.93 & 7.37 & 2.52 & 0.57 & 0.19 & 0.28 & 1.27 \\
\hline & 79 & 172 & 27 & $A B$ & 531 & 0.23 & 28.66 & 14.49 & 5.91 & 8.21 & 2.82 & 0.79 & 0.28 & 0.40 & 3.35 \\
\hline & 79 & 172 & 27 & NB4 & 476 & 0.16 & 25.58 & 13.39 & 5.12 & 7.54 & 2.58 & 0.68 & 0.23 & 0.33 & 0.70 \\
\hline & 79 & 172 & 27 & NB6 & 516 & 0.14 & 27.86 & 13.15 & 4.96 & 7.40 & 2.53 & 0.62 & 0.21 & 0.30 & 1.00 \\
\hline & 79 & 172 & 27 & NB8 & 545 & 0.12 & 29.39 & 12.85 & 4.76 & 7.22 & 2.47 & 0.71 & 0.25 & 0.35 & 1.29 \\
\hline & 79 & 172 & 27 & NB10 & 571 & 0.10 & 30.61 & 12.59 & 4.58 & 7.06 & 2.41 & 0.82 & 0.30 & 0.41 & 1.53 \\
\hline & 96 & 184 & 28 & $A B$ & 563 & 0.25 & 30.22 & 14.80 & 6.14 & 8.40 & 2.89 & 0.86 & 0.31 & 0.43 & 3.62 \\
\hline \multirow{4}{*}{$\begin{array}{c}\text { M54 } \\
\text { p95 }\end{array}$} & 96 & 184 & 28 & NB4 & 519 & 0.20 & 28.05 & 14.06 & 5.59 & 7.95 & 2.73 & 0.85 & 0.28 & 0.41 & 0.68 \\
\hline & 96 & 184 & 28 & NB6 & 676 & 0.19 & 34.71 & 13.90 & 5.48 & 7.85 & 2.70 & 0.88 & 0.29 & 0.42 & 0.98 \\
\hline & 96 & 184 & 28 & NB8 & 704 & 0.18 & 35.55 & 13.75 & 5.37 & 7.76 & 2.66 & 0.85 & 0.28 & 0.40 & 1.00 \\
\hline & 96 & 184 & 28 & NB10 & 703 & 0.19 & 35.53 & 13.87 & 5.46 & 7.83 & 2.69 & 0.83 & 0.28 & 0.40 & 1.14 \\
\hline \multirow{6}{*}{$\begin{array}{l}\text { F54 } \\
\text { p05 }\end{array}$} & 55 & 154 & 23 & $A B$ & 444 & 0.38 & 23.60 & 16.80 & 7.74 & 9.63 & 3.35 & 0.56 & 0.19 & 0.27 & 2.81 \\
\hline & 55 & 154 & 23 & NB4 & 377 & 0.24 & 19.01 & 14.53 & 5.94 & 8.23 & 2.83 & 0.64 & 0.21 & 0.31 & 0.61 \\
\hline & 55 & 154 & 23 & NB6 & 450 & 0.20 & 23.97 & 14.05 & 5.59 & 7.94 & 2.73 & 0.57 & 0.19 & 0.27 & 0.89 \\
\hline & 55 & 154 & 23 & NB8 & 456 & 0.15 & 24.38 & 13.29 & 5.05 & 7.48 & 2.56 & 0.58 & 0.20 & 0.28 & 1.09 \\
\hline & 55 & 154 & 23 & NB10 & 487 & 0.13 & 26.26 & 12.98 & 4.84 & 7.30 & 2.49 & 0.63 & 0.22 & 0.31 & 1.30 \\
\hline & 83 & 172 & 28 & $A B$ & 497 & 0.25 & 26.79 & 14.81 & 6.15 & 8.40 & 2.89 & 1.09 & 0.40 & 55 & 2.59 \\
\hline \multirow{4}{*}{$\begin{array}{c}\text { M64 } \\
\text { p50 }\end{array}$} & 83 & 172 & 28 & NB4 & 538 & 0.18 & 29.04 & 13.69 & 5.33 & 7.72 & 2.65 & 0.58 & 0.19 & 0.29 & 0.83 \\
\hline & 83 & 172 & 28 & NB6 & 592 & 0.16 & 31.53 & 13.47 & 5.18 & 7.60 & 2.60 & 0.65 & 0.21 & 0.32 & 0.94 \\
\hline & 83 & 172 & 28 & NB8 & 635 & 0.16 & 33.27 & 13.41 & 5.14 & 7.56 & 2.59 & 0.75 & 0.24 & 0.39 & 1.21 \\
\hline & 83 & 172 & 28 & NB10 & 624 & 0.13 & 32.87 & 13.01 & 4.86 & 7.32 & 2.50 & 0.70 & 0.25 & 0.35 & 1.44 \\
\hline \multirow{5}{*}{$\begin{array}{l}\text { M64 } \\
\text { p95 }\end{array}$} & 95 & 180 & 29 & $A B$ & 629 & 0.22 & 33.06 & 14.30 & 5.77 & 8.09 & 2.78 & 1.04 & 0.38 & 0.53 & 3.69 \\
\hline & 95 & 180 & 29 & NB4 & 538 & 0.14 & 29.04 & 13.13 & 4.94 & 7.39 & 2.53 & 0.73 & 0.24 & 0.36 & 0.88 \\
\hline & 95 & 180 & 29 & NB6 & 515 & 0.11 & 27.80 & 12.78 & 4.71 & 7.18 & 2.45 & 0.82 & 0.29 & 0.41 & 1.10 \\
\hline & 95 & 180 & 29 & NB8 & 648 & 0.13 & 33.77 & 12.96 & 4.83 & 7.29 & 2.49 & 0.64 & 0.21 & 0.32 & 1.50 \\
\hline & 95 & 180 & 29 & NB10 & 563 & 0.10 & 30.23 & 12.59 & 4.59 & 7.07 & 2.41 & 0.93 & 0.34 & 0.47 & 1.67 \\
\hline \multirow{5}{*}{$\begin{array}{l}\text { F64 } \\
\text { p05 }\end{array}$} & 60 & 154 & 25 & $A B$ & 405 & 0.36 & 20.98 & 16.49 & 7.48 & 9.44 & 3.28 & 0.50 & 0.17 & 0.24 & 2.53 \\
\hline & 60 & 154 & 25 & NB4 & 474 & 0.24 & 25.43 & 14.54 & 5.94 & 8.24 & 2.83 & 0.68 & 0.22 & 0.33 & 0.63 \\
\hline & 60 & 154 & 25 & NB6 & 499 & 0.19 & 26.94 & 13.90 & 5.48 & 7.85 & 2.69 & 0.64 & 0.21 & 0.30 & 0.88 \\
\hline & 60 & 154 & 25 & NB8 & 524 & 0.17 & 28.29 & 13.54 & 5.23 & 7.64 & 2.62 & 0.63 & 0.21 & 0.31 & 1.16 \\
\hline & 60 & 154 & 25 & NB10 & 539 & 0.16 & 29.05 & 13.44 & 5.16 & 7.58 & 2.60 & 0.64 & 0.21 & 0.32 & 1.37 \\
\hline $\begin{array}{l}\text { M28 } \\
\text { p50 }\end{array}$ & 76 & 178 & 24 & -- & 539 & 0. & 07 & 65 & 5. & 7.70 & 4 & 74 & 0.25 & 35 & \\
\hline Max & & & & & 702 & 0.44 & 35.50 & 17.77 & 8.57 & 10.24 & 3.57 & 1.09 & 0.40 & 0.55 & 3.69 \\
\hline Min & & & & & 377 & 0.07 & 19.02 & 12.29 & 4.39 & 6.89 & 2.35 & 0.50 & 0.17 & 0.24 & 0.12 \\
\hline$\varnothing$ & & & & & 454 & 0.09 & 24.19 & 12.52 & 4.54 & 7.02 & 2.40 & 0.60 & 0.20 & 0.29 & 1.16 \\
\hline
\end{tabular}

The maximum value of the $\mathrm{HIC}$ is $702(\mathrm{M}, \mathrm{P} 95,54 \mathrm{YO}, 184 \mathrm{~cm}, 96 \mathrm{~kg} ; 10$ layers nanobag), its minium is $377(\mathrm{M}, \mathrm{P} 05,54 \mathrm{YO}, 154 \mathrm{~cm}, 55 \mathrm{~kg}$, nanobag 4) and the average value is 454 (safety value of HIC). The maximal probability of AIS $2+$ for head and neck are $35.5 \%$ and $19 \%$, respectively. These results suggest safety region of injury risk for all 
safety features. The results also indicate significant increase of head injury risk with the higher impact velocity (AIS2+ for head: $6.73 \%$ and $35.5 \%$ for $30 \mathrm{~km} / \mathrm{h}$ and $50 \mathrm{~km} / \mathrm{h}$ pulse, respective); while the neck injury risk increases in-significantly (AIS2+ for neck: $14.66 \%$ and $17.7 \%$ for $30 \mathrm{~km} / \mathrm{h}$ and $50 \mathrm{~km} / \mathrm{h}$ pulse, respective). The BrIC criterium results with the minimum value 0.5 (F P05, $64 \mathrm{YO}, 154 \mathrm{~cm}, 60 \mathrm{~kg}$ - airbag) and with the maximum 1.09 (M P50, 64 YO, $180 \mathrm{~cm}, 95 \mathrm{~kg}$ - airbag). Generally, the BrIC gives similar values for each particular anthropometry in all configurations. Criterion UBrIC has its minimum MPS value 0.17 (F P05, 14 YO, 153 cm, 41 kg - nanobag 10 layers; F P05, 64 YO, 154 $\mathrm{cm}, 60 \mathrm{~kg}$ - airbag) and the minimum CSDM value 0.24 (F P05, $64 \mathrm{YO}, 154 \mathrm{~cm}, 60 \mathrm{~kg}$ - airbag), while the maximum MPS value is 0.4 (M P50, $64 \mathrm{YO}, 172 \mathrm{~cm}, 83 \mathrm{~kg}$ - airbag) and maximum in CSDM is 0.55 (M P50, $64 \mathrm{YO}, 172 \mathrm{~cm}, 83 \mathrm{~kg}$ - airbag). The UBrIC criterion results in very similar values for the specific anthropometry, however, the maximal values for MPS and CSDM are predicted for the airbag. The minimum contact force is $0.12 \mathrm{kN}$ (M P50, $28 \mathrm{YO}, 178 \mathrm{~cm}, 76 \mathrm{~kg}$ - airbag) and maximum value $3.69 \mathrm{kN}$ (M P95, $64 \mathrm{YO}, 180 \mathrm{~cm}, 95 \mathrm{~kg}$ - airbag). The minimum value is predicted for average male (the size of P50 dummy) with the airbag SRS. Such results confirmed that the passive safety measures (seat belts and airbag) are optimized for this anthropometry. Similarly, to the $30 \mathrm{~km} / \mathrm{h}$ pulse, the results of the crash scenario with no safety features (seat belts only) for average occupant (M, P50, $28 \mathrm{YO}, 178 \mathrm{~cm}, 76 \mathrm{~kg}$ ) are also provided. Table 5 summarise the minimum, maximum and average values for all particular criteria, together with the anthropometry and SRS.

Table 5: Summary of the extreme values of the particular criteria for $50 \mathrm{~km} / \mathrm{h}$

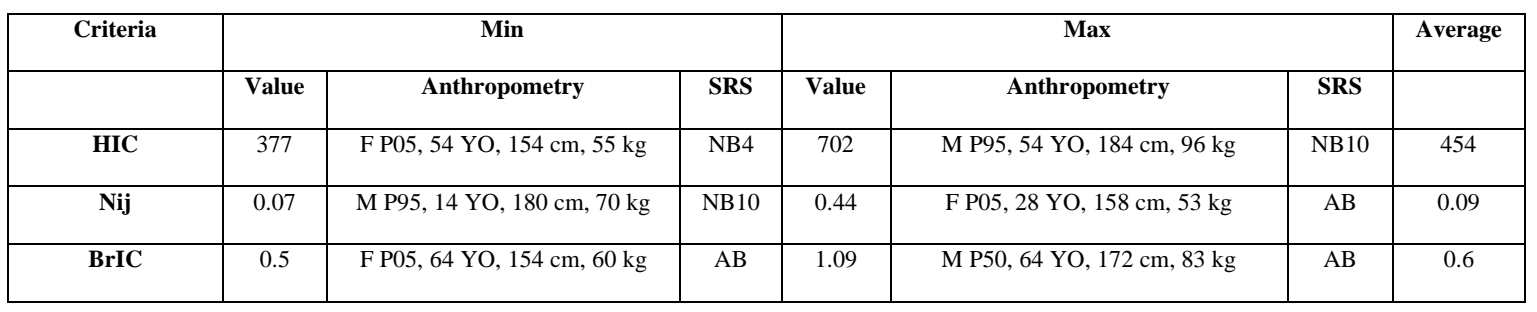




\begin{tabular}{|c|c|c|c|c|c|c|c|}
\hline \multirow{2}{*}{ UBrIC - MPS } & \multirow{2}{*}{0.17} & F P05, $14 \mathrm{YO}, 153 \mathrm{~cm}, 41 \mathrm{~kg}$ & NB10 & \multirow{2}{*}{0.4} & \multirow{2}{*}{ M P50, 64 YO, $172 \mathrm{~cm}, 83 \mathrm{~kg}$} & \multirow{2}{*}{$\mathrm{AB}$} & \multirow{2}{*}{0.2} \\
\hline & & F P05, 64 YO, $154 \mathrm{~cm}, 60 \mathrm{~kg}$ & $\mathrm{AB}$ & & & & \\
\hline UBrIC - CSDM & 0.24 & F P05, 64 YO, $154 \mathrm{~cm}, 60 \mathrm{~kg}$ & $\mathrm{AB}$ & 0.55 & M P50, 64 YO, $172 \mathrm{~cm}, 83 \mathrm{~kg}$ & $\mathrm{AB}$ & 0.29 \\
\hline $\mathrm{Fc}[\mathrm{kN}]$ & 0.12 & M P50, $28 \mathrm{YO}, 178 \mathrm{~cm}, 76 \mathrm{~kg}$ & $\mathrm{AB}$ & 3.69 & M P95, 64 YO, $180 \mathrm{~cm}, 95 \mathrm{~kg}$ & $\mathrm{AB}$ & 1.16 \\
\hline
\end{tabular}

The results of $50 \mathrm{~km} / \mathrm{h}$ impacting velocities also predict the assessment of the nanobag with the safety safety region of head and neck injury risk. Moreover, it also gives similar safety measures to the nanobag and airbag in this specific crash configuration. Most of the extremes values are predicted for the airbag (maximum and minimum) also in the higher velocity impact.

\section{Summary of results}

The results of a frontal sled test exhibit similar performance for the standard airbag and for the nanobag. In the impacting velocity of $30 \mathrm{~km} / \mathrm{h}$, all the HIC values lay within the minor injury risk (max. value is 214 - nanobag). The maximal HIC of all the airbag scenarios is 164 - in the same anthropometry as the total max value of 214 (M, P95, 54 years, $184 \mathrm{~cm}, 96 \mathrm{~kg}$ - NB6). The highest probability of head injury of AIS2+ is $6.7 \%$. The highest neck injury risk is $14.6 \%$ (AIS2+), 6.0 (AIS3+), 8.3 (AIS4+) and 2.9 (AIS5+). AIS 2+ injury is classified as a moderate injury and in case of neck it is considered as a minor laceration of vertebrae or dislocation without fracture.

The scenario with the higher impact velocity $(50 \mathrm{~km} / \mathrm{h})$ results in higher injury risk for head and neck respectively. The maximal HIC value is 702 (acceptable injury) (M, P95, 54 years, $184 \mathrm{~cm}, 96 \mathrm{~kg}-\mathrm{NB} 10$ ), while the average is 520 (minor injury - good condition of survivability for human), (Hobbs, C.A. et al, 1998). The maximal HIC of all the airbag scenarios is $595(\mathrm{M}, \mathrm{P} 50,44$ years, $174 \mathrm{~cm}, 79 \mathrm{~kg})$. The highest probability of 
head injury of AIS2+ is $35.5 \%$. The highest neck injury risk is $17.7 \%$ (AIS2+), 8.6 (AIS3+), 10.2 (AIS4+) and 3.6 (AIS5+). All the values of injury risk lay within the safety region. The results suggest that increasing of the impact velocity affects more the head then the neck injury risk; Head AIS2+: $6.7(30 \mathrm{~km} / \mathrm{h})$ and $35.5(50 \mathrm{~km} / \mathrm{h})$; and Neck AIS2+: $14.7(30 \mathrm{~km} / \mathrm{h})$ and $17.7(50 \mathrm{~km} / \mathrm{h})$. The brain soft tissue injury criteria (BrIC and UBrIC) and maximum contact force result similarly for all particular scenarios (both impacting velocities and all configurations).

\section{Conclusion}

The benefits of the nanobag solution lie in the minimization of the volume of the folded nanobag, minimization of the weight, simplicity of the technology production and a low cost of material inputs, including the assembly and maintenance. The system can be easily adapted for the nonstandard seating positions (tightly connected with the autonomous vehicles), where side, oblique or rear direction of impact are to be occurred. The performance of the standard airbag is assumed to lost its benefit in such configurations. The numerical simulations with the application of human body models as a surrogate for the occupant could led to the faster progress in the field of safety measure optimization for diverse society. The nanobag safety system shows comparable performance to the traditional airbag solution in the frontal direction impact. It gives another possible safety solution for the car developers and enable them to build the future car safer also for such scenarios. The suggested technology does not try to replace the airbag, it only suggests the new technical solution, which, of course, could have some pros and cons, especially prototype of the mechanical system based on nanobag must be tested in real full-scale setup, to be certified. However, the safety effect is expected to be beneficial and comparable to the traditional airbag. 


\section{Acknowledgements}

This work is supported by the European Regional Development Fund-Project "Application of Modern Technologies in Medicine and Industry" (No. CZ.02.1.01/0.0/0.0/17_048/0007280), by the internal grant project “Computer modelling and monitoring of human body used for medicine" (No. SGS-2019-002) and by the John H. and Amy Bowles Lawrence Foundation.

\section{References}

Bláha, P. (1987). Antropometrie československé populace od 6 do 55 let. Ústř. štáb Čs. spartakiády 1985 .

Bońkowski T, Hyncik L, Lv W. 2019. Numerical Assessment of Motorcyclist Accident. Journal of the Society of Automotive Engineers Malaysia 3(2):210-217.

ESI Group, http://www.esi-group.com/software-solutions/virtual-performance/virtualperformance-solution

Hanuliak A. 2018. Safety Restraint System for Motor Vehicles. Radali Spol. s.r.o., Mátl, Roman, Havlík, Martin. PV 2017-307 (CZ). B60R 21/08 (2006.01). WO2018/219371. Valid from 19 November 2018. Signed 6 December 2018.

Happee R, De Vlugt E, Schouten AC. 2008. Posture maintenance of the human upper extremity; identification of intrinsic and reflex based contributions. SAE International Journal of Passenger Cars - Mechanical Systems 1:1125-1135.

Hobbs, C. A, McDonough, P. J. 1998. Development of the European new car assessment programme (Euro NCAP). Regulation, 1998, 44.3.

Hynčík L, Čechová H, Kovář L, Bláha P. 2013. On Scaling Virtual Human Models. SAE Technical Paper No. 2013-01-0074. doi: 10.4271/2013-01-0074.

Hynčík L, Kochová P, Špička J, Bońkowski T, Cimrman R, Kaňáková S, Kottner R, Pašek M. 2021. Identification of LLDPE Constitutive Material Model for Energy 
Absorption in Impact Applications. Polymers 2021, 13(10), 1537. doi: 10.3390/polym 13101537 .

Hynčík L, Maňas J, Špička J, Špirk S, et al. 2014 Development of 6 Years Old Child Virtual Model by Automatic Scaling. SAE Technical Paper 2014-01-2028. doi: 10.4271/2014-01-2028.

Hynčík, L., Špička, J., Maňas, J., Vychytil, J. (2015). Stature Based Approach towards Vehicle Safety (No. 2015-26-0209). SAE Technical Paper.

Gabler, L. F., Crandall, J. R., Panzer, M. B. (2018). Development of a metric for predicting brain strain responses using head kinematics. Annals of biomedical engineering, 46(7), 972-985.

Gabler, L. F., Crandall, J. R., Panzer, M. B. (2019). Development of a second-order system for rapid estimation of maximum brain strain. Annals of biomedical engineering, 47(9), 1971-1981.

Jorlöv S, Bohman K, Larsson A. 2017. Seating Positions and Activities in Highly Automated Cars - A Qualitative Study of Future Automated Driving Scenarios. Proceedings of International Research Council on the Biomechanics of Injury (IRCOBI) Conference, 13 - 15 September, Antwerp, Belgium. ISSN: 2235-3151

Lindstedt L, Vychytil J, Dziewwonski T, Hynčík L. 2016 Numerical tests of the virtual human model response under dynamic load conditions defined in federal aviation regulation part 23.562 and 25.562 - preliminary study. Archive of Mechanical Engineering LXIII(4):511-530. doi: 10.1515/meceng-2016-0029.

Lv W, Hynčík L, Bonkowski T. 2019 Rider Stature Influence to Injury Risk in Motorcycle Rear Impact to Car. SAE Technical Paper 2019-01-1436. doi:10.4271/201901-1436.

Paul G, Scataglini S. 2019. DHM and Posturography. Elsevier Science. ISBN: 9780128167137.

Schmitt KU, et al. 2013. Trauma biomechanics: Introduction to accidental injury. Springer Science \& Business Media. ISBN 978-3-642-53920-6. 
Sahoo, D., Coulongeat, F., Fuerst, F., \& Marini, G. Comparison of Head Injury Criteria Based on Real-World Accident Simulations under Visual Performance Solution (VPS).

Vezin P, Garnier K, Bermond F, Verriest JP. 2002. Comparison of Hybrid III, Thor-alfa and PMHS response in frontal sled tests. Stapp Car Crash Journal 46:1-26. doi: 10.4271/2002-22-0001.

Vychytil J, Maňas J, Čechová H, Špirk S, Hynčík L, Kovář L. 2014. Scalable multipurpose virtual Human model for future safety assessment. SAE Technical Paper No. 2014-01-0534. doi: 10.4271/2014-01-0534.

Wang JZ, Li J, Pallavajhala K, Zhou Z, Hu J, Boyle K, Reed M. (2019) THOR 50M Suitability for Automated Vehicle Crashworthiness. Proceedings of the ESV Conference, Paper no. 19-0162, Eindhoven, The Netherlands

Wheeler, J. B., Smith, T., Siegmund, G. P., Brault, J. R., King, D. J. (1998, September). Validation of the neck injury criterion (NIC) using kinematic and clinical results from human subjects in rear-end collisions. In Proceedings of the International IRCOBI Conference on the biomechanics of impacts (pp. 335-348). 
Appendix 